\title{
A DAILY RECORD OF ULTRAVIOLET SOLAR AND SKY RADIATION IN WASHINGTON, 1941 TO 1943
}

\author{
By W. W. Coblentz and R. Stair
}

ABSTRACT

A description is given of a photoelectric ultraviolet-intensity meter and automatic integrating and recording apparatus for measuring the biologically effective component of ultraviolet radiation, of wavelengths $3132 \mathrm{~A}$ and shorter, from the sun and the entire sky, incident on a horizontal plane, under various meteorological conditions. Methods of standardization, in absolute value, are described (see RP1542 for supplementary data). A continuous graphical record of the integrated daily total amount of biologically effective ultraviolet solar and sky radiation observed during a period of 3 years (1941 to 1943) in Washington, D. C. is given. The monthly totals of biologically effective ultraviolet, in absolute value (milliwatt minutes per square centimeter) $\mathrm{mw} \mathrm{min} / \mathrm{cm}^{2}$ are also given graphically. On the clearest days the biologically effective component of ultraviolet radiation of wavelengths $3132 \mathrm{~A}$ and shorter, incident from the sun and the whole sky at midday, ranges from about 180 microwatts per square centimeter, $\left(\mu \mathrm{w} / \mathrm{cm}^{2}\right)$ in midsummer to about $30 \mu \mathrm{w} / \mathrm{cm}^{2}$ in midwinter. A series of erythema tests is given, correlating the physical (radiometric) measurements with the physiological reaction of the untanned skin, which information is of interest in helotherapy and bioclimatology.

\section{CONTENTS}

Page

I. Introduction

II. Instruments and methods

1. Description of the ultraviolet meters

2. Standardization of the ultraviolet meters _........... 27

(a) Sample determination of the conversion factor, $I_{\ldots} \ldots \ldots 30$

III. Discussion of the data

1. Effect of clouds

2. Summary of measurements

IV. Erythema tests with ultraviolet solar and sky radiation

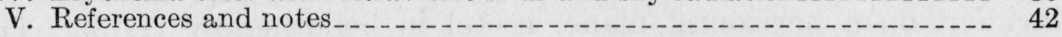

\section{INTRODUCTION}

An important problem in bioclimatology is the securing of a continuous radiometric record of the total daily amount of biologically effective ultraviolet radiation from the sun and from the entire sky, incident on a horizontal plane, as a function of the season and the geographic latitude $[1,6] .^{1}$

As noted in a previous paper [2], the evaluation of the biologically effective ultraviolet solar radiation is still in its infancy, and the uncertainties involved are somewhat comparable with those experienced in the beginning of the evaluation of the total incident solar radiation of all wavelengths half a century ago. However, there is

\footnotetext{
${ }_{1}$ Numbers in brackets indicate the literature references and notes at the end of this paper.
} 
this distinction, that whereas the evaluation of the total solar radiation is made with a radiometer that is practically nonselective to all the wavelengths incident on the earth's surface and can be easily calibrated in absolute units, the evaluation of the biologically effective ultraviolet component of sky and solar radiation is made with a radiometer that is selectively responsive to only a narrow band of wavelengths, and hence is difficult to calibrate in absolute units.

A further difficulty arises from the fact that the energy value of the biologically effective component of ultraviolet radiation of wavelengths $3132 \mathrm{~A}$ and shorter usually is less than a thousandth part of the total incident solar radiation. Hence, a much more sensitive (consequently less stable) radiometer is required to evaluate the ultraviolet component than the total incident solar and sky radiation of all wavelengths.

Variations in ozone concentration in the stratosphere and atmospheric pollution by smoke and dust have a greater effect upon the ultraviolet radiation of short wavelengths than upon the longer wavelengths included in the measurement of the total incident solar and sky radiation. Hence, the total amount of ultraviolet radiation received at two closely situated stations (especially in thickly populated localities) may differ greatly, depending upon dust, smoke, and the direction of the prevailing wind. It is therefore, a question of the extent of the refinements in accuracy that should be attempted in a long-range daily evaluation of biologically effective ultraviolet solar and sky radiation of interest in climatology, as differing from a highly accurate evaluation in connection with an irradiation test of short duration, involving a specific biological (erythemal, antirachitic, tanning, etc.) reaction.

In the present investigation the type of construction of a standard ultraviolet solar and sky intensity meter that will operate continuously under extreme weather conditions (heat, cold, snow, rain, sunshine) could not be anticipated without preliminary experiments. Earlier efforts were begun about 9 years ago when the problem was presented to secure a continuous record of the total incident, biologically effective ultraviolet solar and sky radiation $[3,18,19,20]$ for use in irradiating animals.

The data summarized in the present paper were obtained as a byproduct in connection with an investigation of photoelectric instruments and methods of measuring ultraviolet solar and sky radiation incident on a horizontal plane, useful in heliotherapy [1, 3]. This investigation has involved an examination of the response (with respect to wavelength and angle of incidence of the exciting radiation), and the constancy of performance under normal operation, of more than a dozen phototubes [7] of $\mathrm{Mg}$ [3] and of $\mathrm{Ti}$ and $\mathrm{Zr}$ [8], some of which were constructed for study by one of the writers [1]. Others. were constructed for field use by the Department of Agriculture [24] and by the National Institute of Health [8] and for use as primary standards to be maintained by the National Bureau of Standards [4].

As was to be expected, with the development and improvement in performance of suitable photoelectric cells, this type of ultraviolet intensity meter is finding applications in other fields, for example, in connection with tests of weathering of materials (cotton) in the field [24]. 


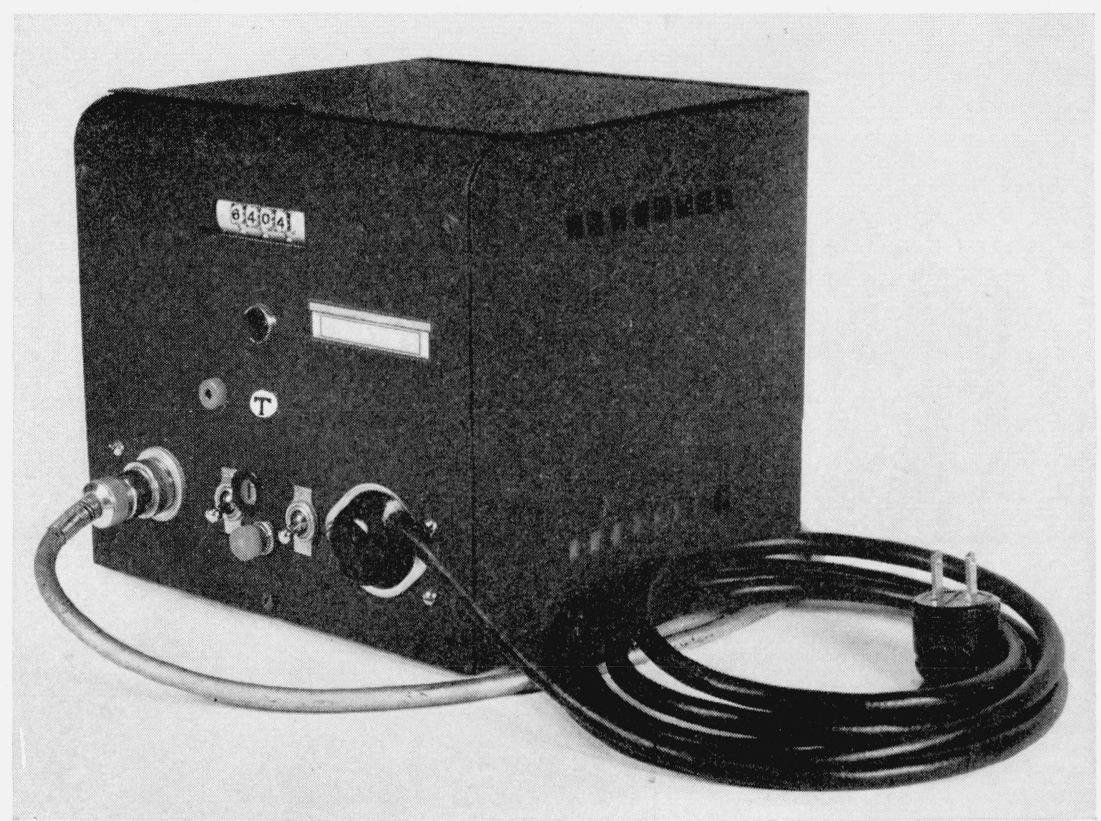

FiGURE 1.-Metal box containing rectifier tubes, relay, and an impulse ("message") counter.

Connection with automatic impulse counter and recorder is made at $T$. The right-hand outlet is not visible. 


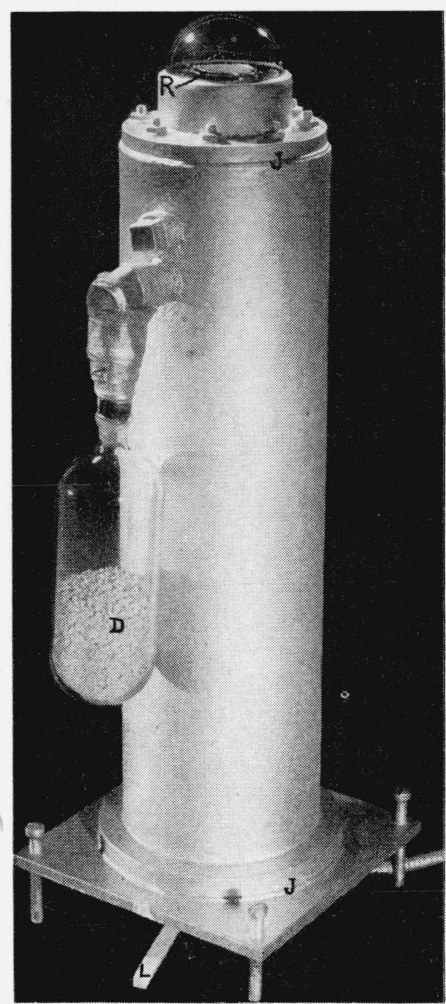

Figure 2.-Mg-phototube in brass housing containing two "trigger tubes," air condenser, and drying material, $D$.

Lever arm, $L$, is for interchanging trigger tubes. The photosensitive receiver, $R$, measures the ultraviolet solar and sky radiation incident on a horizontal plane. The bright spots are unavoidable reflections of the light sources used in making the photograph-see figure 3 .

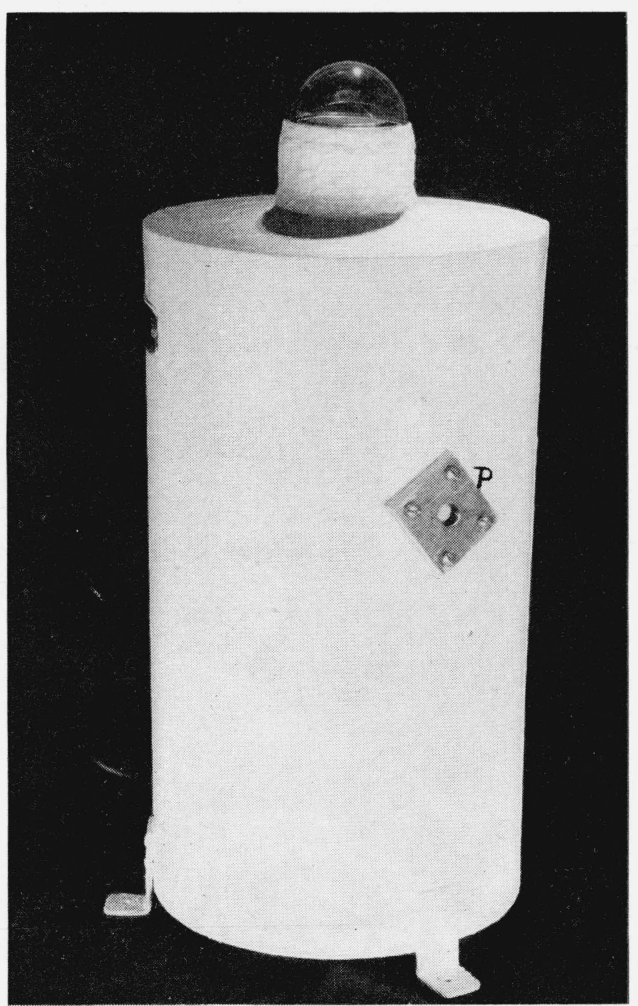

FIGURE 3.-Zr-phototube supported in metal housing.

Shadowing device is attached at $P$. 
As already noted, the securing of statistical data on ultraviolet solar and sky radiation of use in bioclimatology is just beginning. In this connection, reference is made to two researches. The first is by Kenrick and his collaborators [19, 20,21], who measured ultraviolet intensities from the sun and from an appreciable portion of the surrounding sky in San Juan, P. R., using a Ti-phototube mounted upon a polar axis, whereby the semicylindric receiver was kept directed normal to the incident solar radiation $[3,18]$. The measurements were continued for 2 years (1937-39). The sensitivity of the phototube was checked periodically by means of a quartz mercury-arc lamp calibrated against the Bureau's primary standard of ultraviolet radiation [11]. Outstanding among their observations is an increase in ultraviolet radiation by reflection from clouds - a phenomenon that will be discussed in the present paper.

The second paper of interest in bioclimatology, by Luckiesh and his collaborators [22], gives a continuous 4-year record (1935-38, inclusive) of ultraviolet solar and sky radiation incident on a horizontal plane in the suburbs of Cleveland, Ohio. The photoelectric cell was a pear-shaped glass bulb, about $6 \mathrm{~cm}$ in diameter, the interior of which was sensitized by an opaque layer of cadmium, with a clear area about $3 \mathrm{~cm}$ in diameter on one side of the glass bulb to admit solar and sky radiation to the photosensitive interior (see fig. 1 of RP1075 [17a]. Outstanding among their observations is the large amount of ultraviolet radiation received from the whole sky, as herein recorded and as previously noted, particularly by Dannmeyer [4, 23]. Based upon observations of this type, heliotherapy by sky irradiation may prove useful in cases where direct solar irradiation cannot be employed [35].

\section{INSTRUMENTS AND METHODS}

Taking into consideration ever-changing sky conditions, it is desirable to use a quick-acting, integrating ultraviolet radiant-flux meter to secure climatological data on the amount of biologically effective ultraviolet solar and sky radiation incident at a given station.

The particular ultraviolet radiant-flux integrating device investigated consisted of three parts: (a) an electronic integrating device, comprising a new type of phototube for intercepting ultraviolet solar and sky radiation incident on a horizontal plane [3], an electric condenser, and a grid-glow ("trigger") tube [5], which combination was inclosed in a suitable chamber that was mounted on the roof of a building, (b) a metal box (fig. 1), within the laboratory, containing a relay, rectifier tubes, and an impulse ("message") counter [5] made by R. J. Cashman [3]; and, supplementing this counter, (c) an automatic impulse counter and recorder, consisting of a modified commercial photoelectrically operated traffic recorder that was connected (at $T$ in fig. 1) in parallel with the impulse counter. This recorder registered the impulses received from the photoelectric integrator, and, at quarter-hour intervals, printed on a strip of paper [4] the day, the hour, and quarter-hour, and the total number of incoming impulses. In this manner, in addition to the reading on the impulse (message) counter, a permanent printed record was obtained of the number of impulses and, hence of the total amount of ultraviolet solar and sky radiation. Controlled by an a-c-driven clock, the ultraviolet inte- 
grating meter and recorder were operated only during the daytime.

It is relevant to note that in the operation of the device, the photoelectric cell, on exposure to ultraviolet radiation, emits electrons, i. e., conducts a current that charges a condenser to a critical voltage, at which voltage the condenser is discharged through an impulse-counting mechanism, and that the charging of the condenser is repeated at a rate that is proportional to the intensity of the incident ultraviolet radiation, which varies with the solar altitude and with ever-changing weather conditions. Knowing the energy required to charge the condenser to a critical voltage (the "microwatt-seconds" factor, $I$, for converting an impulse into energy units), it is a simple matter to obtain from the printed record the number of impulses per unit time (half-hour, hour, day), and hence the total amount of biologically effective ultraviolet radiation received each day.

In some of the Eppley thermoelectric pyrheliometers (Kimball design [25]) for measuring solar and sky radiation incident on a horizontal plane the voltage conversion-factor (millivolts per gram-calory) is the same for all solar heights. Similarly, the finding of a photoelectric cell having the same impulse conversion factor ( 1 impulse $=$ $x \mu \mathrm{w} \mathrm{sec} / \mathrm{cm}^{2}$ ) for all solar heights seems accidental. Apparently it depends principally upon the spectral transmission of the glass enclosure, the spectral response of the photosensitive surface, and the response with angle of incidence of the exciting radiation upon the receiver.

It is shown, beginning on page 30 , that with the Mg-phototubes (which had a characteristic response with respect to the wavelength of the exciting radiation, and a response with angle of incidence that coincided closely with that predicted by the cosine law) the conversion factor varied with the solar height (see fig. 3 of [4]). Hence, in calculating the herein-described data, obtained with phototubes $\mathrm{Mg}-2$ and $\mathrm{Mg}-41-1$, a different conversion factor (microwatt-seconds per square centimeter) had to be applied to the impulses received during each half-hour of the day. On the other hand, for a number of the Zr-phototubes, particularly $\mathrm{Zr}$-15, used in the present investigation, within the experimental errors of making the calibration the same conversion factor was applicable to all the impulses recorded throughout the day. It was therefore a simple matter to deduct the printed morning reading from the evening reading, thus securing the total number of impulses and, by applying a single conversion factor, the total amount of biologically effective ultraviolet solar and sky radiation per day. Obviously, with such cells and impulse counters in operation it would not be necessary to tabulate the data oftener than once per week or month.

\section{DESCRIPTION OF THE ULTRAVIOLET METERS}

Two types of ultraviolet intensity meters, in their mounting, were investigated. Unforeseen difficulties in the development of the device prevented an intercomparison of these meters with a proposed third type of ultraviolet meter [30].

In the first type of mounting shown in figure 2, the Mg-phototube (fig. 3 of [3]) is cemented into a moisture-proof, cylindrical brass housing. The auxiliary apparatus, consisting of a variable air condenser, a suitable resistance, and two grid-glow (trigger) tubes, WL 
759 [5] (one for constant use, the other for infrequent use to check the constancy of the former and to replace it if necessary) is mounted on a chassis within the metal housing. The trigger tubes were interchanged by means of a switch that was connected (through a moistureproof joint) to a lever arm beneath the housing, shown at $L$ in figure 2 . During the 10 months that the constancy of the trigger tubes was under observation, no systematic change (if any) in the discharge rate greater than 2 percent was observed. The question of constancy of the discharge rate, therefore, needs no further discussion. Our observations are in agreement with the claims of the manufacturer, that, barring defective samples, there is no deterioration in the discharge rate with usage of these trigger tubes.

The variable air condenser was connected with a shockproof metal rod that extended through the bottom of the container. After adjusting the capacitance of the condenser to produce 15 or 20 discharges ("impulses", "clicks") per minute under maximum ultraviolet irradiation of the phototube, the end of the rod was covered with an airtight metal cap, which remained undisturbed during the 18 months that this phototube, $\mathrm{Mg}-41-1$, was under observation. The interior of the metal housing was kept dry by means of anhydrous $\mathrm{CaSO}_{4}$ ("indicating") in a glass container, $D$, figure 2. The joints, $J$, in the housing were covered with aluminum paint. If any moisture entered the housing, it was not sufficient to change the blue color of the indicator during the 2 years that elapsed after the device was assembled.

This part of the apparatus was securely mounted on the parapet of the roof of a four-story building, which permitted exposure of the photoelectric receiver to the whole sky.

The construction of four of these phototubes in their mountings was undertaken by R. J. Cashman for the Council on Physical Therapy [1] - two for use at his station (Evanston, Ill.) and two for use at the National Bureau of Standards as primary standards and for comparison of ultraviolet intensities at these two stations. Unfortunately, this program was interrupted by military matters.

In view of the novelty of the phenomenon, it is of interest to record a type of deterioration that occurred in phototube $\mathrm{Mg}-41-1$ (fig. 2), which had an excellent cosine response with angle of incidence and, at the beginning of the measurements, was a promising primary standard. In this type of photoelectric cell the anode usually consists of two bow-shaped metal wires at right angles to each other (see fig. 3). In order to determine the effect (if any) of the shape of the anode upon the critical voltage in this particular cell (fig. 2), the anode consisted of a flat grid of six wires (three at right angles to each other) parallel with and about $8 \mathrm{~mm}$ above the plane of the photosensitive cathode, $R$.

After being in operation continuously for 14 months, in July 1942 the impulse rate of this cell began to increase, presumably as a result of an increase in sensitivity in the long wavelengths. A small (3 $\mathrm{mm}$ ) spot, with a metallic luster, developed on the top of the glass dome and a faintly brownish-colored spot appeared on the side, on a level with the cathode. In the course of the next 3 months the photosensitivity increased by 26 percent, and the dome showed six faintly brownish-colored bands (three at right angles to each other), each 
about $3 \mathrm{~mm}$ in width, directly over the six fine wires forming the anode. Moreover, vertically above the 9 intersections of the wires, and over most of the 12 right-angled bends in these wires, these bands of discoloration were darker and rectangular or triangular in outline. The intersection of the two dark bands in the center of the glass dome was rectangular in outline, and within this rectangular area of discoloration was a circular darker-colored area. This central dark area, as well as several others, and part of the adjacent uncolored glass was covered with minute $(0.01 \mathrm{~mm}$ diameter, some circular) dark specks - apparently the beginning of a disintegration of the glass by electron bombardment.

In the second type of mounting investigated the auxiliary apparatus (consisting of a condenser of suitable capacitance and a grid-glow tube) was mounted in an evacuated glass tube sealed to the Zr-phototube [8].

The flat receiver [3], which is about $35 \mathrm{~mm}$ in diameter, is a modification of the semicylindric photosensitive receiver of $\mathrm{Ti}$ [5] originally used in this type of photoelectric cell [8], (see fig. 2 of [9] and fig. 1 of $[10])$.

The complete tube, which is about $6 \mathrm{~cm}$ in diameter and about 40 $\mathrm{cm}$ long, is mounted in a suitable metal housing, with only the top part exposed, as shown in figure 3. The leveling, which need not be very accurate, is accomplished by means of suitable wooden blocks placed under the supports, which are securely attached to the parapet of the roof.

In the early models of $\mathrm{Zr}$-phototubes employing this type of construction the accumulation of electric charges on the interior of the glass dome (of high-silica glass) suppressed the emission of electrons from the photosensitive receiver. This suppression of electron emission was erratic, sometimes continuing for 2 to 3 hours in the early forenoon. It was partially remedied by Stair by placing a guard ring around the outside, at the level of the receiver, and connecting it (through a 1-megohm resistance) with the positive line to the phototube. In some of the Mg-phototubes (see fig. 3 of [3]), the guard ring of evaporated metal or of Aquadac (colloidal carbon) was on the interior of the phototube. It is probable that the glass (Corning No. 972) used in the Mg-phototubes [3] dissipated the electric charges more readily than the high-silica glass used in the Zr-phototubes.

To eliminate the eff ect of electric charges, in the most recent models of $\mathrm{Zr}$-phototubes the photosensitive receiver is inclosed in a larger glass bulb (about $8 \mathrm{~cm}$. in diameter) than previously employed, thereby practically doubling the distance of the receiver from the glass dome. In this model, wiping the glass bulb has no effect upon the photoelectric emission. Although the external guard ring is retained, in view of the fact that its use on the smaller glass bulbs did not entirely prevent suppression of electron emission, by electric charges when the glass was wiped, it would appear that the solution of this problem is in the use of a larger-sized glass bulb. Another improvement consists in placing a small drainage tube at the bottom of the phototube, so that if moisture seeps in at the top it cannot accumulate and short-circuit the lead-in wires, as was experienced in the early models. 


\section{STANDARDIZATION OF THE ULTRAVIOLET METERS}

For use as a primary standard of measurement, in absolute value, of the biologically effective component of ultraviolet solar and sky radiation incident on a horizontal plane, the logical procedure would be to standardize the radiometer in terms of homogeneous radiation of wavelength $2967 \mathrm{~A}$, as previously proposed $[9,11]$ for instruments used in measuring solar radiation at normal incidence. Thus far, however, this procedure has not been practicable for either type of instrument. Hence, in connection with the use of instruments for measuring solar and sky radiation incident on a horizontal plane, two methods of standardization [4] were undertaken: (a) by calibration against a standard of ultraviolet radiation [11], and (b) by calibration against an ultravioletintensity meter [3, 9] that measures radiation incident normal to the photoelectric receiver [2]. The latter was calibrated against a standard of ultraviolet radiation [11] and gave ultraviolet solar-radiation intensities, of wavelengths shorter than $3132 \mathrm{~A}$, in close agreement with measurements made with a balanced thermopile [12, 13, 14], which was calibrated against a standard of thermal radiation [15]. Since the measurements made with the balanced thermopile (see figs. 4, 5, and 6 of [12]) were in good agreement with those obtained with a single thermocouple receiver that had been calibrated in absolute value by means of a standard pyrheliometer, the above method (b) of calibration is based upon three standardized sources of radiation-the sun $[12,28]$, a standard of thermal radiation [15], and a standard of ultraviolet radiation [11].

In a recent paper on this subject (p. 437 and 443 of [2], also p. 323 of [14]), it was noted that the level of all the measurements may be uniformly too high or too low, primarily because of the difficulty in determining the spectral-energy distribution in the biologically effective band of ultraviolet solar radiation, of wavelengths $3132 \mathrm{~A}$ and shorter, and, hence, the uncertainty of the factor used in calculating the data. The accuracy attainable in the measurement of the biologically effective component of ultraviolet solar radiation, in absolute value, is therefore somewhat of a conjecture. However, as noted elsewhere $[14,16]$ and from the herein-described erythema tests (which are in accord with previous tests $[12,13])$, the good agreement in the measurements of the biologically effective component of ultraviolet solar radiation of wavelengths $3132 \mathrm{~A}$ and shorter, obtained with spectrally nonselective thermopiles and with wavelength selective radiometers differing greatly in range of spectral photoelectric response, appears to be real and not the result of a fortuitous combination of factors, including (a) the spectral responses of the photoelectric cells [2, 31, 32, 34], (b) the spectral transmissions of the filters, and (c) the transmissions of the integrated ultraviolet solar radiation through the various filters $[10,33]$. Hence, although the production and calibration of a primary standard ultraviolet radiometer is incomplete, it is believed that the degree of accuracy attained in the calibration of the instruments used in the present investigation is as high as warranted by the constancy of the behavior of the photoelectric cells now available and the irregularity of meteorological conditions experienced from day to day.

Because of the exigency of other activities and the lack of time to work out the factors involved in the above-mentioned method (a), it seemed best, at the time, to standardize the ultraviolet meters (which 
are easily disturbed by handling) by a method that permits a calibration of the instruments in place, undisturbed as used in practice. This method, (b), in which the various factors have been worked out during the past 10 years, consists in measuring the ultraviolet solar intensity in absolute value $\left(\mu \mathrm{w} / \mathrm{cm}^{2}\right)$ incident normally, with a standard ultraviolet intensity meter [9, 2]. Simultaneously, a measurement was obtained of the combined ultraviolet solar and sky radiation, and (by intercepting the direct solar beam with an occulting screen) of only the sky radiation incident on the horizontal photocell receiver (see p. 155 of [3]).

This is the procedure of the United States Weather Bureau in calibrating pyrheliometers used for measuring the total sky and solar radiation incident on a horizontal plane [26]. It places the uncertainty of the calibration upon the pyrheliometer designed for measuring radiation at normal incidence, and, as above noted, in the case of the nonselective pyrheliometer there is half a century of research on the accuracy attainable. In the case of the spectrally selective radiometer (photocell), because of the above-noted uncertainty in the energy distribution in the biologically effective band of ultraviolet solar radiation, high accuracy in the absolute values is not yet attainable (p. 443 of [2]).

The occulting screens used with the photoelectric cells were blackened rubber balls, $30 \mathrm{~mm}$ in diameter, for shadowing the receivers, 25 $\mathrm{mm}$ in diameter, and blackened spherical balls of balsa wood, $43 \mathrm{~mm}$ in diameter, for shadowing the receivers, $38 \mathrm{~mm}$ in diameter. By actual trial it was found that balls $2 \mathrm{~mm}$ larger, and smaller, in diameter had no effect upon the impulse rate ("clicks"), showing that radiometrically as well as visually the shadowing from the direct solar rays was complete. These occulting balls were attached to a thin wooden rod, about $50 \mathrm{~cm}$ long, that was mounted on a polar axis, attached at $P$ in figure 3 . They were about $60 \mathrm{~cm}$ from the receiver.

For convenience in securing an accurate time scale, the impulses were recorded by means of a graphic milliammeter (see fig. 4 of RP1075 [17a]) operated by a synchronous motor. For this purpose the graphic recorder was temporarily connected in parallel (at $T$, fig. 1) with the impulse counter and printing recorder.

The electric discharges (impulses) from the ultraviolet meter produced a series of galvanometer deflections (ink lines about $5 \mathrm{~mm}$ long) on the recording sheet. The intervals between these ink lines (impulses) were, of course, longer during the period of shadowing of the receiver than during the period of exposure to the sun and the sky. Except when the altitude of the sun was low, a fixed schedule of recording was usually followed: (a) an exposure of the phototube for 2 min to the sun and sky, followed (b) by a 3-min interval of shadowing of the receiver from direct sunlight, i. e., exposure to the sky. This schedule was repeated every $5 \mathrm{~min}$, in succession, for 1 to $5 \mathrm{hr}$. The distance between the 1-min intervals ruled on the recording paper (see fig. 4 of RP1075 [17a] )was $19.2 \mathrm{~mm}$. By measuring the distance recorded between 5 to 15 lines (impulses), recorded in the 2- to 3-min intervals allotted to each set of observations, a high precision was attained in the measurement of the impulse rate, i. e., the ultraviolet radiant flux from the sky and from the sun.

Provided with an accurate time scale, which was recorded with the graphic milliammeter, on deducting the ultraviolet sky radiation from 
the total (sun + sky), the ratio of intensities (impulses per unit timethe fractional impulse per second in the instruments used) of sky radiation to solar radiation incident on a horizontal plane is easily determined. As shown in figure 4, the biologically effective component of ultraviolet radiation from the whole (cloudless) sky incident upon a horizontal surface depends upon the solar height (air mass traversed by the direct solar rays) and upon atmospheric turbidity. Even during the clearest days, at a practically sea-level station (Washington), the ultraviolet component of sky radiation is rarely less than (and usually it is 2 to 5 times greater than) that of direct solar radiation (see fig. 4).

From the measurement of the ultraviolet solar radiation incident normally (reduced to incidence on a horizontal plane [29]) and the ratio of ultraviolet sky radiation to solar radiation, the total solar and sky radiation incident on a horizontal plane is easily determined.

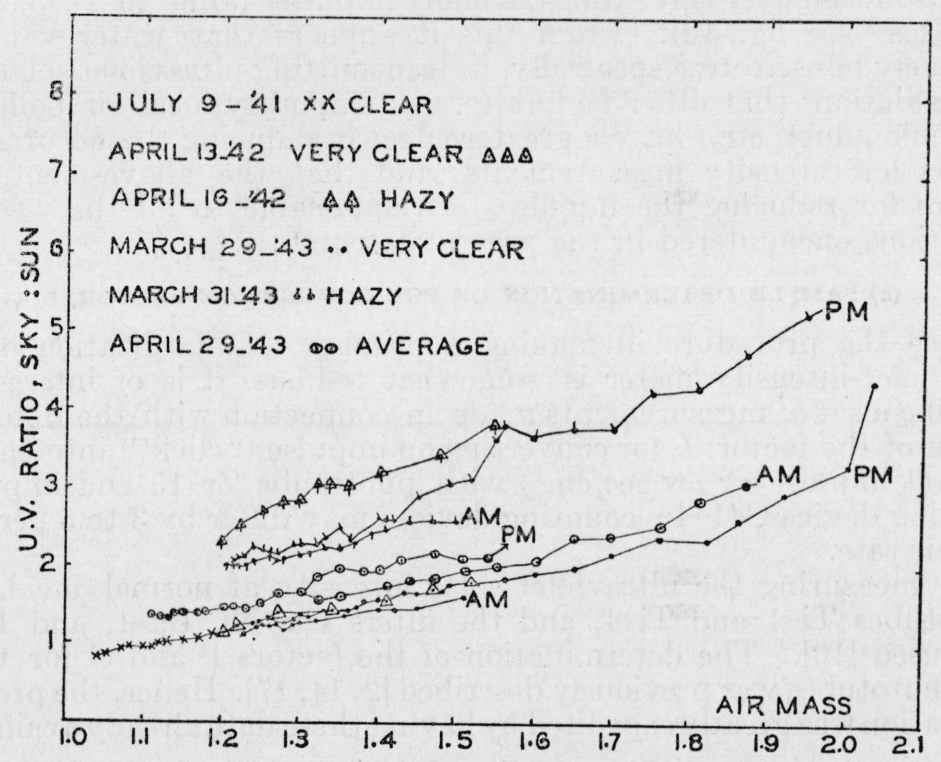

FigURE 4.-Measurements of ratios of ultraviolet sky and solar radiation incident on a horizontal plane.

From the measurement of the total ultraviolet solar and sky radiation, incident on a horizontal plane, the factor for converting an impulse into energy units ( $\mu \mathrm{w} \mathrm{sec} / \mathrm{cm}^{2}$, the ultraviolet solar energy effective in charging the condenser to produce one "click") is derived. A typical set of solar and sky radiation measurements and the derivation of a conversion factor are given at the end of this chapter.

As noted in the preceding paper [2], the measurements of ultraviolet solar radiation incident normally upon wavelength-selective and nonselective radiometers are in good agreement. Hence, the present measurements are made consistently on the same basis and ean be revised if eventually such a revision is required.

It is to be noted that these cal brations were made on the clearest days. The factors for reducing the impulses are, therefore, average 
values for clear-weather conditions. Naturally, the question arises regarding the factors for overcast skies. From earlier studies [10] it appears that fog and clouds of water vapor reduce the incident spectral ultraviolet radiation relatively nonselectively, whereas dust and smoke behave like an opaque screen.

An intercomparison of Zr-phototubes differing (a) in intrinsic sensitivity, (b) in response with angle of incidence of irradiation ("cosine response"), and (c) in range of spectral response, sometimes showed short-period variations in the ratios of impulses recorded that appeared to be attributable to variations in transparency of ozone in the stratosphere. However, based upon an extensive intercomparison of phototubes $\mathrm{Zr}-53$, $\mathrm{Zr}-15$, and $\mathrm{Mg}-3$, differing in sensitivity by, roughly, $1: 2: 3$, the ratio of the total impulses per day $(1: 2.17: 2.80)$ was the same within 2 to 3 percent on cloudy days (e. g., July 8, 1943, 1,428 impulses with phototube $\mathrm{Zr}$-15 - see fig. 10) as on fairly clear days that produced over three times as many impulses (June 26, 1943, 4,640 impulses-see fig. 10). From this it appears that water vapor is relatively nonselective spectrally, in transmitting ultraviolet solar and sky radiation; that other factors (e. g., temporary local air pollution by smoke, dust, etc.) have a greater effect in reducing the accuracy of ultraviolet intensity measurements; and that the above-mentioned factors for reducing the impulses are applicable to all the weather conditions encountered in the present research.

(a) SAMPLE DETERMINATION OF THE CONVERSION FACTOR, $I$

Since the procedure in making a primary standardization of an ultraviolet-intensity meter is somewhat tedious, it is of interest to describe a set of measurements made in connection with the determination of the factor, $I$, for converting an impulse ("click") into energy units ( 1 impulse $=x \mu \mathrm{w} \mathrm{sec} / \mathrm{cm}^{2}$ ) with phototube $\mathrm{Zr}-15$ and impulsecounting device C41-4-counting devices may differ by 3 to 5 percent in their rate.

For measuring the ultraviolet solar intensity at normal incidence, phototubes $\mathrm{Ti}-1$ and $\mathrm{Ti}-4$, and the filters $\mathrm{Cx}, \mathrm{Ni}, \mathrm{Ba}-1$, and $\mathrm{Ba}-3$ were used [10]. The determination of the factors $P$ and $G$ for these two phototubes was previously described $[2,14,17]$. Hence, the present calibration was greatly expedited by having these data already available.

The following is a partial transcription of the data obtained at 11:20 to 11:27 a. m. on April 29, 1943.

I. Sun, normal incidence; phototube Ti-4. Time 11:22 to 11:27 a. m. Air mass, $m=1.12$; solar height $63.5^{\circ}($ sine $=0.895)$. Observed solarintensity $=62.2$ $\mu \mathrm{w} / \mathrm{cm}^{2} ;=55.7 \mu \mathrm{w} / \mathrm{m}^{2}$ on a horizontal plane.

II. Sun + sky, incident on a horizontal plane; phototube $\mathrm{Zr}-15$. Time 11:20 to $11: 22 \mathrm{a} . \mathrm{m}$. Average of 10 and of 15 clicks; 1 click $=1.90 \mathrm{~mm}$ on the recorder chart ( $1 \mathrm{~mm}=3.16 \mathrm{sec}$.); same value at 11:25 to $11: 27 \mathrm{a}$. m., 1 click in $(1.90 \times 3.16=) 6.01$ sec $(0.1665$ click in $1 \mathrm{sec})$.

III. Sky radiation; $11: 22$ to $11: 25 \mathrm{a} . \mathrm{m}$. Average of 10 and of 15 clicks; 1 click= $3.305 \mathrm{~mm}$ on recorder chart $(1 \mathrm{~mm}=3.16 \mathrm{sec})$. 1 click in $10.44 \mathrm{sec}(0.0958$ click in $1 \mathrm{sec}$ ).

Solar radiation produced $(0.1665-0.0958=) 0.0707$ click in 1 sec.

Ratio of sky to solar radiation $(0.0958 \div 0.0707=) 1.355$.

Total solar+sky radiation [55.7 $+(1.355 \times 55.7=] 131.2 \mu \mathrm{w} / \mathrm{cm}^{2}$.

Factor, $I=131.2 \times 6.01=788 \mu \mathrm{w} / \mathrm{sec} / \mathrm{cm}^{2}$.

In connection with the foregoing record of observations, it is relevant to note that on April 29, 1943, in the forenoon, upper-air conditions underwent sudden variations; from "clear blue, small 
white corona" to a few "thin cirrus-fracto clouds" that disappeared in a few minutes. From 8:57 to 9:10 a. m. (air mass, $m=1.51$ to 1.44) a faint "sun dog" was visible, followed by murkiness and an occasional thin fracto cloud. In spite of these variations, the ratios for the integrated ultraviolet of the whole sky relative to the direct solar radiation are fairly uniform - see figure 4 .

As shown in a previous paper (fig. 3 of [4]), the factor for converting impulses into ultraviolet intensities, measured with phototube Mg-41-1 varied with the solar height. In that illustration the calibration pertains to the wavelength range of $3200 \mathrm{~A}$ and shorter. For the herein-used spectral range of $3132 \mathrm{~A}$ and shorter, the factor is reduced by about one-half at air mass 1.1 and decreases practically linearly with increase in air mass.

Using ultraviolet meter $\mathrm{Zr}-15$, the factor, $I$, did not vary with the (air mass) solar height, the average value being 1 impulse $=780 \mu \mathrm{W}$ $\mathrm{sec} / \mathrm{cm}^{2}$. This fortunate circumstance simplified the calculations, for it was necessary simply to multiply the total impulses per day by the factor $I$, instead of summing the values recorded each half hour. As noted in the beginning of this chapter, in some of the Eppley pyrheliometers the same factor (millivolts per gram-calory) obtains throughout the day.

\section{DISCUSSION OF THE DATA}

- The herein-described data on ultraviolet solar and sky radiation of wave lengths $3132 \mathrm{~A}$ and shorter were obtained with instruments mounted on the parapet of the roof of the South Building of the National Bureau of Standards, latitude $38^{\circ} 56.5^{\prime \prime} \mathrm{N}$, longitude $77^{\circ} 4^{\prime}$ $\mathrm{W}$, elevation about $410 \mathrm{ft}$ above sea level. The locality is practically residential, in the northwest section of Washington, D. C. There are no factories, and most of the atmospheric pollution (by the combustion products of automobiles, incinerators, oil burners, and coal furnaces in office buildings and apartment houses) occurs southeast of the Bureau. The prevailing wind is from the west or northwest quadrant, where the suburban Maryland villages (no factories) are few, and there is no dense smoke. Only on very rare occasions, such as mentioned on p. 953 and 964 of [28], is a dense, low-lying, stratum of smoke and finely divided particles of dust carried over this locality by an east wind. The stratum of smoke from railroad engines, office apartment buildings, etc., that is visible some 4 miles to the southeast, may intercept direct solar radiation in the early morning in winter. No doubt there is a pall of atmospheric pollution over this city, similar to that observable on the clearest days, low on the northnortheast horizon, presumably over the city of Baltimore, some 30 miles distant.

On the clearest days in the winter and spring the wind may be from the north instead of the northwest, and a light "smoke" (dry coal dust) that occasionally issues from a tall chimney, situated due north, may be blown over the photoelectric receivers. This, however, is of infrequent occurrence and of short duration. Hence, considered as a whole, the herein presented data are representative of localities, in this latitude, relatively free from local atmospheric pollution and having similar meteorological conditions.

$592615-44-5$ 


\section{EFFECT OF CLOUDS}

It is well recognized that the amount of ultraviolet solar radiation reaching any spot on the earth's surface is determined by the amount of ozone in the stratosphere; also by local atmospheric pollution (by smoke and dust) and by the distribution of clouds in the lower atmosphere.

In the $\mathrm{Zr}$-phototubes the response is somewhat higher than predicted by the cosine law, with angle of incidence. Hence, under

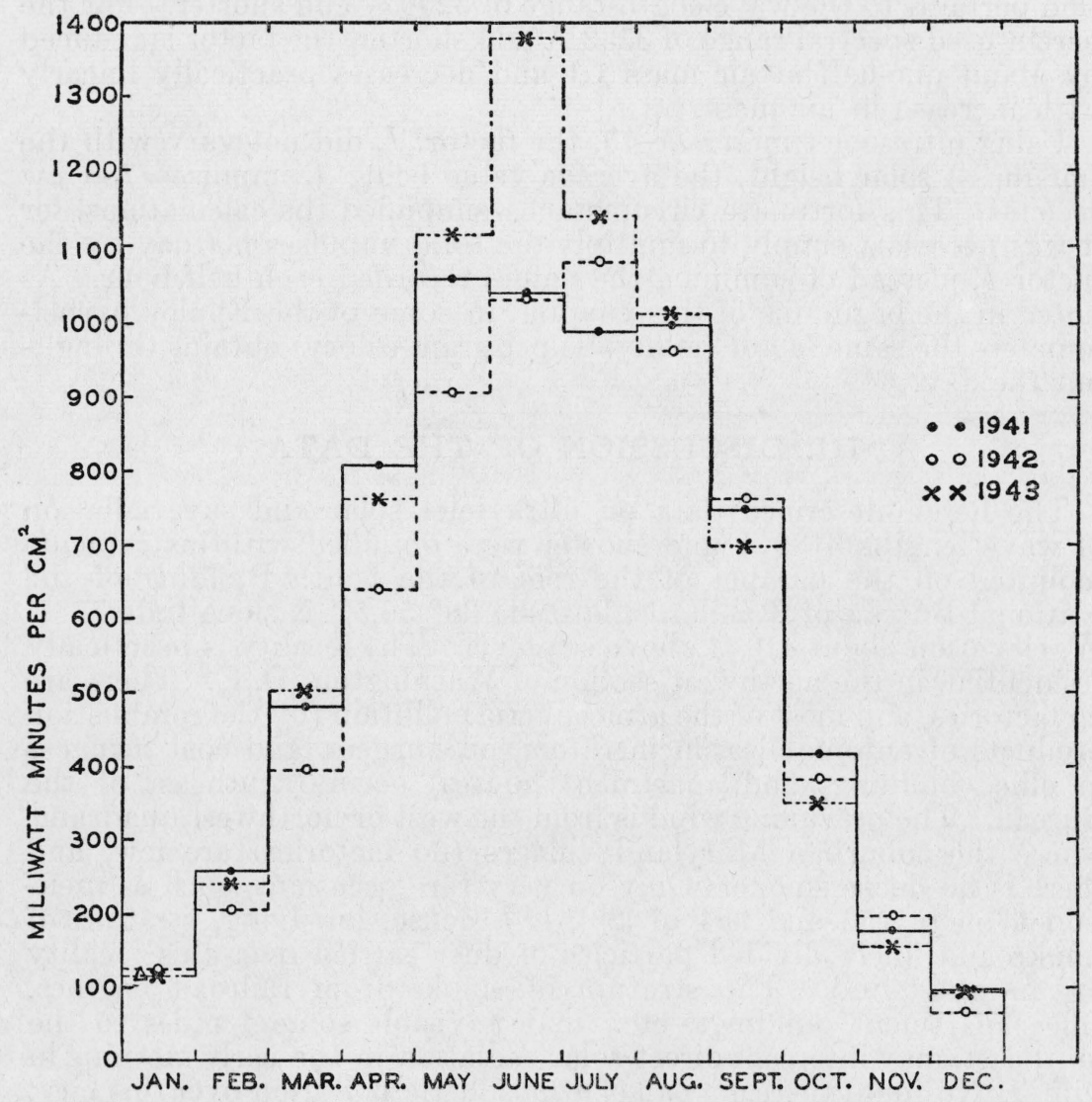

FIGURE 5.-Monthly totals of biologically effective ultraviolet solar and sky radiation, in milliwatt minutes per square centimeter, incident on a horizontal plane, in Washington, D. C., during the years 1941 to 1943, inclusive (also Jan. 1944, $\Delta \Delta$ ).

These data were calculated from observations depicted in figures 8,9 , and 10 .

certain cloud distributions the number of impulses produced by ultraviolet radiation may be greater than expected. This, however, does not greatly affect the average values, and it does not explain the high values obtained with certain kinds of cloud formations, viz, small fleecy clouds, near but not in the line of sight with the sun, as noted by other observers [19, 20,22].

For example, on June 28, 1943, which was listed as "hot and partly sloudy", an exceptionally large number of impulses $(4,858)$ was re- 
recorded (see fig. 10). There was a high wind and large, rapidly moving fracto-cumulus clouds. The intervening sky was exceptionally clear, blue (not "contrast blue"), and free from turbidity. At the noon-hour the impulses were 14 to 15 per min-an exceptionally high rate, even on the clearest days. In contrast, on June 4, which was listed "clear with a few thin cirrus-fracto clouds at $10 \mathrm{a} . \mathrm{m}$. and 1 p. m.", the total number of impulses $(4,942)$ recorded was not conspicuously larger, (see fig. 10), than noted above for June 28. The length of day and the air masses traversed by the direct solar rays were practically the same on these two dates. Apparently the fracto-cumulus clouds reflected an appreciable amount of ultraviolet radiation.

The month of June 1943 was conspicuous for low precipitation, but numerous days of partial cloudiness - fracto-cumulus, altcumulus, and cirro-cumulus. Nevertheless, the total amount of ultraviolet received is exceptionally large (see fig. 5). In contrast, in the month of July 1943, which also had low precipitation and much cloudiness of the nimbus type, the total ultraviolet received is much

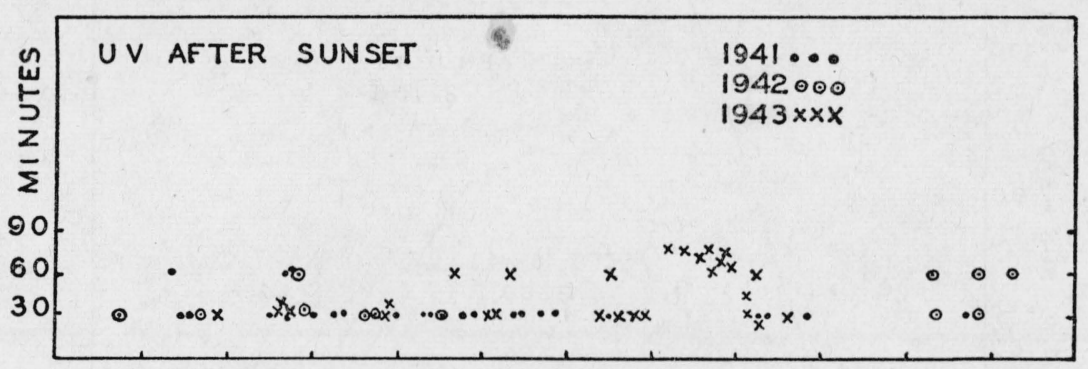

JAN. FEB. MAR. APR. MAY JUNE JULY AUG. SEP. OGT. NOV. DEC.

FiguRE 6.-Conspicuous instances of ultraviolet sky radiation incident during evening twilight-time in minutes after sunset.

lower (see fig. 5). In fact, during the first week in July the total incident ultraviolet solar and sky radiation was only about 60 percent of that of the last week in June.

As noted in previous papers [2], the atmospheric transparency to ultraviolet radiation is greater in the fall than in the spring; also greater in the afternoon than in the forenoon. This was repeatedly observed in the present measurements when the recorder registered impulses at sunset and 30 to $60 \mathrm{~min}$ thereafter. As shown in figure 6, this occurred in different years. For example, in 1943 there seemed to be a large number in the latter part of August (an excessively dry month) and the first part of September. The nonoccurrence in October is probably fortuitous.

Evidently, these impulses were produced by ultraviolet solar radiation that entered the upper atmosphere and was reflected downward from near the zenith upon the ultraviolet meter [37]. The intensity, of course, is very low, as indicated by the slow charging of the condenser to a critical voltage. For example, on December 6, 1942 (cloudy day, sky clear in the evening, sunset at about 4:45 p. m.) no impulses were recorded between $4: 15 \mathrm{p}$. m. and 5:45 p. m. and only 
1 impulse at $6 \mathrm{p}$. m., which was produced by the charge accumulated during the interval beginning half an hour before sunset and ending about an hour after sunset. Similarly, with the group observed in the latter part of August 1943-see figure 6. From earlier (negative) tests made during moonlight nights [4b] it appears highly improbable that these occasional impulses were caused by artifical sources but were due to a partial charging of the condenser by upper-air ultraviolet sky radiation, before sunset, and the completion of the charging, to the critical voltage, during twilight on evenings when the sky was exceptionally clear.

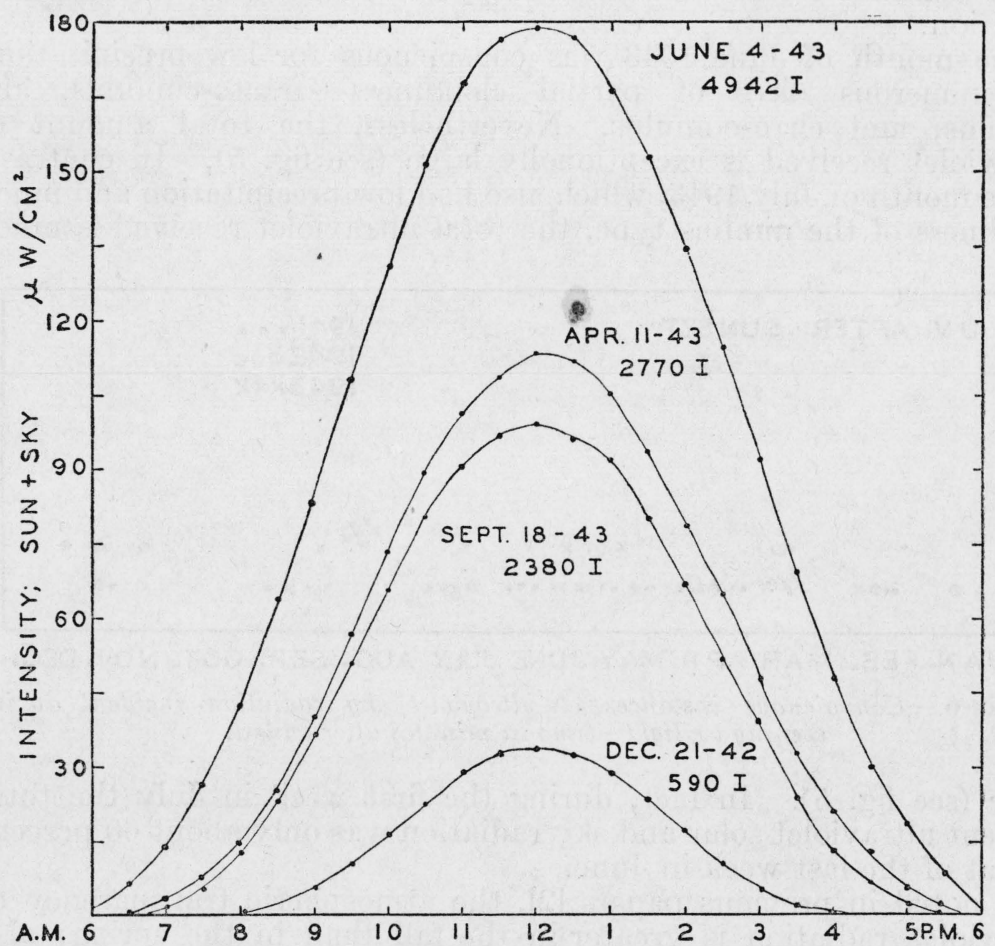

FIGURE 7.-Daily and seasonal variation in intensities of ultraviolet solar and sky radiation incident on a horizontal plane, in microwatts per square centimeter (also total impulses, $I$ ), observed on four very clear days in Washingion, $D$. C.

Measurements made with phototube $\mathrm{Zr}-15$.

\section{SUMMARY OF MEASUREMENTS}

In previous publications $[2,14]$, it is shown that on the clearest days, at the noon hour, in Washington, the ultraviolet solar intensity of wavelengths $3132 \mathrm{~A}$ and shorter at normal incidence ranges from about $75 \mu \mathrm{w} / \mathrm{cm}^{2}$ in June to one-sixth this value in December. For comparison, in figure 7 are depicted the average intensities of solar and sky radiation incident on a horizontal plane on four very clear days in Washington. These values are calculated from the printed records of impulses received during half-hour intervals. The intensities of combined solar and sky radiation, incident on a horizontal plane, 
at midday, ranged from about $180 \mu \mathrm{w} / \mathrm{cm}^{2}$ on a very clear day in June to $33 \mu \mathrm{w} / \mathrm{cm}^{2}$ (about one-sixth the summer value) in December [4].

From the foregoing paragraph it is interesting to note that, for these two seasons, the ratio of intensities of ultraviolet solar radiation at normal incidence and of total ultraviolet solar and sky radiation incident on a horizontal plane are not conspicuously different. This of course might be expected. As shown in figure 4, for low solar altitudes the sky contributes most of the ultraviolet incident on a horizontal plane. Only on the clearest days and for air masses less than $m=1.1$, at a sea-level station, is the intensity of the directly incident, biologically effective ultraviolet solar radiation equal to, or greater than, that of the diffusely reflected ultraviolet radiation from the whole sky incident on a horizontal surface.

In these illustrations the numbers (590 I in fig. 7; also fig. 8, etc.) are the total impulses recorded during the day. Using the calibration (conversion) factor, 1 impulse $=780 \mu \mathrm{w} / \mathrm{cm}^{2}$, the daily totals, in energy units, ranged from $7.68 \mathrm{mw} \mathrm{min} / \mathrm{cm}^{2}(\mathrm{mw}=$ milliwatt) on December 21,1942 to $64.3 \mathrm{mw} \mathrm{min} / \mathrm{cm}^{2}$ on June 4,1943 - see figure 5 for monthly totals.

In figures 8, 9, and 10 are depicted the total daily impulses recorded and, hence, measurements of the total ultraviolet solar and skyradiation incident at the Washington station during the period beginning February 1, 1941 and continuing without interruption through December, 1943. In figure 10 ( $\mathrm{Zr}-15$-different sensitivity) the scale of ordinates is different from that of figures 8 and 9 . This is eliminated by the conversion factor, which is different for each photoelectric cell used in this research. It has already been noted that unusually high values of ultraviolet intensities were recorded on certain cloudy days. No doubt interesting bioclimatological information will be obtained when such measurements can be continued systematically over a long period. For example, September 29, 1943 was a clear day, and, contrary to expectation, a relatively low number $(1,157)$ of impulses was recorded. The barometer had been high for 2 days and continued high until noon the following day. This usually indicates a low ozone concentration in the stratosphere. Apparently there was already (a "cold front"), an inflow of polar air, producing an increase in ozone concentration in the stratosphere preceding the decrease in barometric pressure [36] and the cloudy weather that occurred the following day.

Supplementing the observations depicted in figures 8, 9, and 10, the total impulses per month were converted into energy (e. g., for $\mathrm{Zr}-15,1$ impulse $\left.=780 \mu \mathrm{w} \mathrm{sec} / \mathrm{cm}^{2}\right)$. These monthly values are shown in figure 5. As is to be expected, the high values recorded in April, August, and September 1941, and in June, July, and August 1943, are evident from an inspection of the large clear areas under the graphs in figures 8 and 10 .

Considering the fact that it does not require a great difference in cloudiness to affect the daily and monthly totals, especially in the summer months, the monthly totals for these 3 years are remarkably close in magnitude, except for the months of May, June, and July 1943. With an excessively large number of days with temperatures above $33^{\circ} \mathrm{C}\left(90^{\circ} \mathrm{F}\right.$; the largest number of days in half a century) and a low precipitation during June, July, and August, the much higher values of the integrated ultraviolet intensities in 1943 than observed 


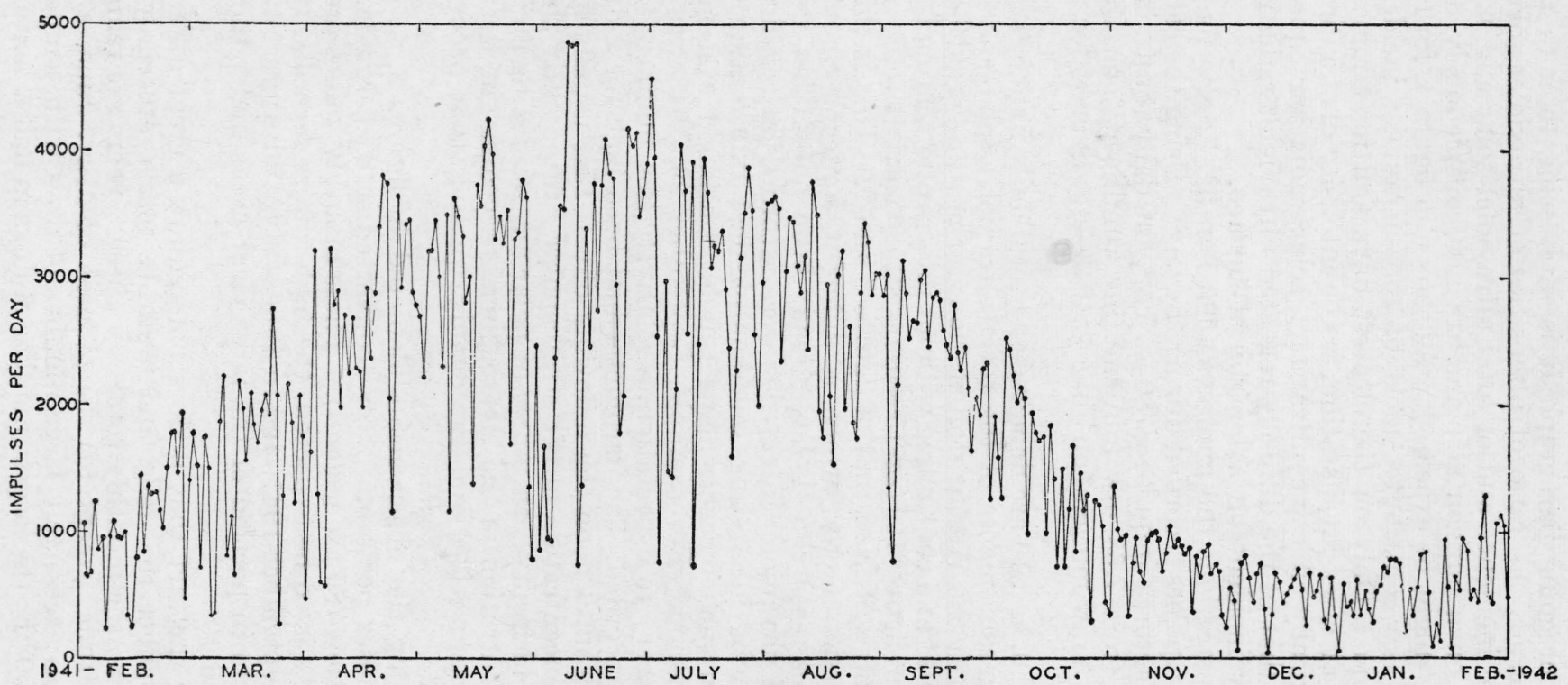

ईू

FIGURE 8.-Impulses per day, and hence, a relative measurement of the total integrated daily amount of biologically effective ultraviolet solar and sky radiation incident in Washington, D. C., in 1941.

Measurements with Mg-2, (February to June) and with Mg-41-1 phototubes. 


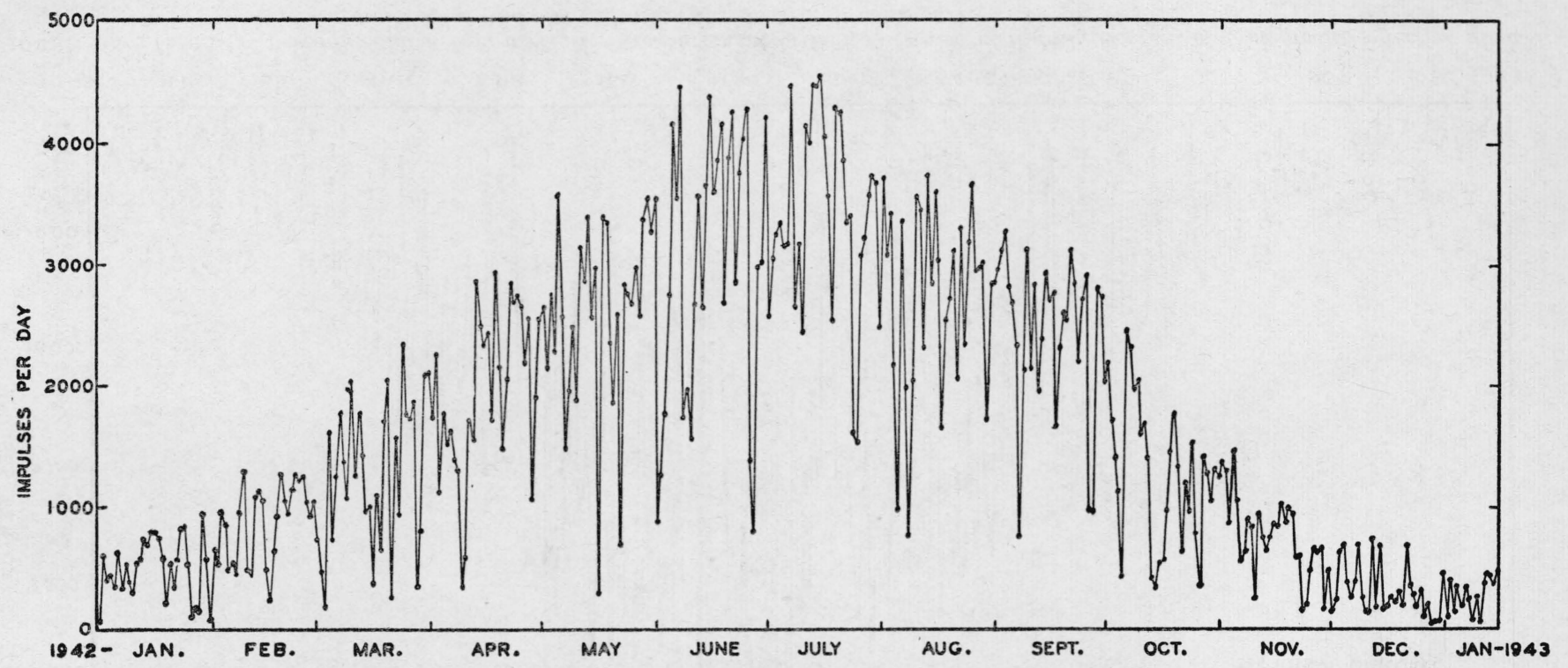

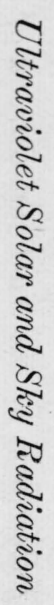

FIGURE 9.-Impulses per day, and hence, a relative measurement of the total integrated daily amount of biologically effective ultraviolet solar and sky radiation incident in Washington, D. C., in 1942.

Measurements with Mg-41-1, and with $\mathrm{Zr}-15$ (in November and December). 


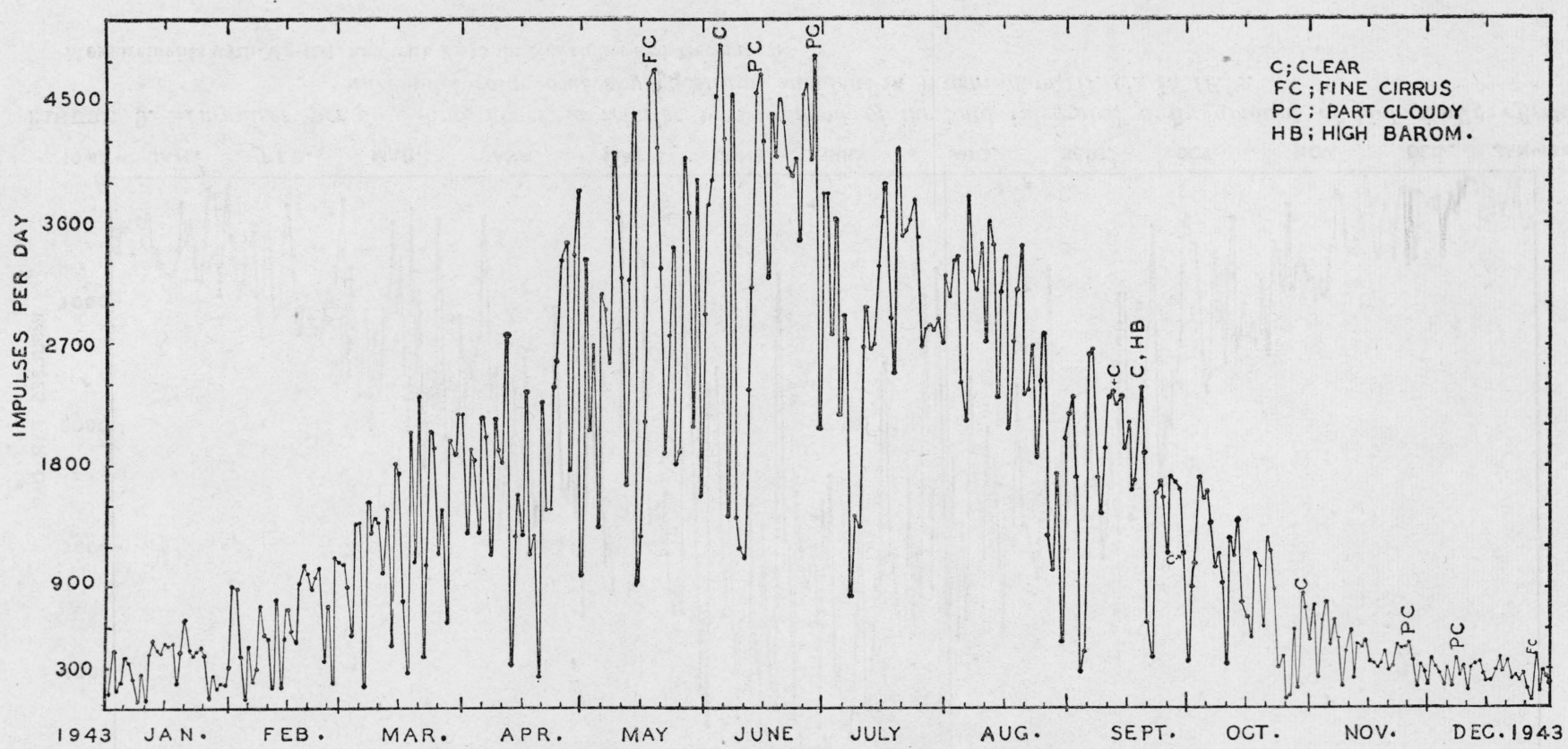


during the preceding 2 years are easily accounted for on the basis of clearer weather.

Because of the impossibility of obtaining delivery of an adequate supply of good photoelectric cells for a continuous intercomparison of performance of a group of cells, the calibration of the ultraviolet intensity meters used in the present research was made by direct standardization of each instrument, as above described.

There is, therefore, no doubt a small uncertainty in the intercomparison of the monthly data obtained during different years. However, the values have been reduced by the factor 60,000 (to milliwatt-minutes). Hence, statistically and climatologically, the monthly sums, shown graphically in figure 5, can be regarded satisfactory for present purposes. Similar large variations in the monthly values, extending over an interval of 4 years, are shown in figure 3 of [22]. In fact, from the records of the great variations in the monthly averages of total solar radiation, similar variations in the ultraviolet component of solar and sky radiation are to be expected.

A conspicuous feature in figure 5 is the great difference in the seasonal values of ultraviolet solar and sky radiation, with much higher values in the autumn. This great difference is especially noticeable in the months of comparable solar heights, March and September, April and August, February and October, and January and November. As noted in a previous paper [2], this is due to the presence of a less amount of ozone in the stratosphere (hence, a greater amount of incident ultraviolet solar radiation) in the autumn than in the spring.

\section{ERYTHEMA TESTS WITH ULTRAVIOLET SOLAR AND SKY RADIATION}

In previous papers $[12,13]$ data are given on the erythematogenic efficiency of heterogeneous ultraviolet radiation from the sun and from artificial sources of radiation, at normal incidence, using homogeneous radiation of wavelength $2967 \mathrm{~A}$ as a comparison standard. It was therefore of interest to obtain measurements of the erythematogenic effectiveness of ultraviolet solar and sky radiation incident on a horizontal plane. If there is a marked difference in the spectral composition of sky and direct solar radiation or in the calibration of these two types of ultraviolet-intensity meters, it should be observable in the total energy required to produce a minimum perceptible erythema, when using a combination in which the sky radiation is 2 to 3 times the amount of solar radiation. From the herein-described erythema tests apparently there is no marked difference in the spectral composition of sky and solar radiation. Hence, no attempt was made to prolong this part of the investigation, using the refinements of comparison with the standard of homogeneous radiation of wavelength 2967 A described in previous papers [12, 13].

In making these erythemal exposure tests the untanned part of the inner side of the upper arm was covered with a cardboard shield perforated with a row of seven holes, each about $4.5 \mathrm{~mm}$ in diameter, as shown in figures 1 and 2 of [27]. A sliding cover of white cardboard permitted individual exposures ranging from 8 to $90 \mathrm{~min}$. The rest of the arm was covered with a white cloth to prevent sunburn and tanning. 
In making the exposures to solar and sky radiation the observer faced south, with the arm resting on a support placed on the parapet of the roof, a short distance from the ultraviolet-intensity meter. The arm was extended horizontally, on a level with the shoulder, and, since the amount of ultraviolet sky radiation incident from levels near the horizon is extremely small [22], no correction was made for shadowing by the head.

Test No. 1.- June 19, 1943; sky cloudless, except on the east horizon; hot, very light breeze; between 10:50 (Eastern Standard Time; air mass, $m=1.07$ ) and 11:23 a. m., seven exposures were made of, respectively, $10,15,20,23,26,29$, and $33 \mathrm{~min}$.

All but the first exposure $(10 \mathrm{~min}$.) showed erythema that continued for 24 hours and pigmentation that continued for several months. It was difficult to decide when erythema ceased and pigmentation began.

The ultraviolet intensity (u.v.Q) ranged from 150 to $158 \mu \mathrm{w} / \mathrm{cm}^{2}$, average $155 \mu \mathrm{w} / \mathrm{cm}^{2}$. The time for a minimum perceptible erythema (M. P. E.) was estimated at 13 to $14 \mathrm{~min}$, or an expenditure of $(155 \times 13 \times 60 \times 10=) 1,210,000$ to $1,300,000 \mathrm{ergs} / \mathrm{cm}^{2}$. The recorder registered $175 \mathrm{impulses}(1 \mathrm{impulse}=780$ $\left.\mu \mathrm{W} \mathrm{sec} / \mathrm{cm}^{2}\right)$ in $15 \mathrm{~min}$, indicating $(175 \times 780=) 136,500 \mu \mathrm{w} \mathrm{sec} / \mathrm{cm}^{2}$, or $1,365,000$ ergs $/ \mathrm{cm}^{2}$ as a maximum to produce an M. P. E. These values are in good agreement with earlier determinations on the same subject (W. W. C. [12, 13]) exposed to solar radiation at normal incidence and to a small area of the surrounding sky radiation. In those erythema tests the exposures were made with a tall building as a background and tall trees at the sides and in the foreground, which excluded about 85 percent of the sky radiation. The ultraviolet solar radiation stimulus (88 to $90 \mu \mathrm{w} / \mathrm{cm}^{2}$ ) was therefore 10 to 15 percent higher than the recently reported values ( 75 to $78 \mu \mathrm{w} / \mathrm{cm}^{2}$ for normal incidence), which included but little sky radiation [2]. Two determinations (on June 2 and on July 22, 1931) required $1,728,000$ and $1,056,000 \mathrm{ergs} / \mathrm{cm}^{2}$, respectively, to produce an M. P. E., which is in as close agreement as can be expected in making the biological appraisal.

Test No. 2.-June 26, 1943; sky murky; very hot, very light or no breeze; between 10:45 and 11:03 a.m., seven exposures of, respectively, 8, 10, 11, 12, 13, 15, and $18 \mathrm{~min}$ thin cirrus, and a large fracto cloud near the sun at 10:53 to 10:58 a. m.

Exposures Nos. 3 (11 $\mathrm{min})$ to $7(18 \mathrm{~min})$, inclusive, showed erythema (No. 7 , very red) at 8 p. m. Exposures Nos. 5, 6, and 7 were still visible on the following evening. No. $7(18 \mathrm{~min})$ showed about the same pigmentation as No. $2(15 \mathrm{~min})$ of June 19. Three days later Nos. 5, 6, and 7 showed very faint pigmentation.

The u.v.Q ranged from 156 to $162 \mu \mathrm{w} / \mathrm{cm}^{2}$, average $160 \mu \mathrm{w} / \mathrm{cm}^{2}$. The time for an M. P. E. was estimated at 12 to $13 \mathrm{~min}$, or an expenditure of $1,150,000$ to $1,250,000 \mathrm{ergs} / \mathrm{cm}^{2}$. The recorder registered 183 impluses in $15 \mathrm{~min}$, indicating $(183 \times 780=) 142,600 \mu \mathrm{w} \mathrm{sec} / \mathrm{cm}^{2}$, or $1,426,000 \mathrm{ergs} / \mathrm{cm}^{2}$ as a maximum.

These measurements were made during excessively hot weather, with air temperatures above $90^{\circ} \mathrm{F}\left(33^{\circ} \mathrm{C}\right)$. It is therefore an interesting question as to what effect excessive perspiration had upon erythema and particularly upon pigmentation, which seemed much less than in the 15-min exposure in the preceding test.

In these tests no measurements were made of the amount contributed by sky radiation. In the first test the sky was clear and the ratio of solar radiation to sky radiation was estimated to be about $1: 1.3$. In the second test the ratio of solar to sky radiation was probably 1:2.5, or perhaps higher for a short time when a large fracto cloud was near the sun. With variable sky conditions the advantage of using the photoelectric ultraviolet integrating device in measuring the ultraviolet radiation stimulus during the biological test is obvious.

Test No. 3.- July 1, 1943; cool, light breeze; at the beginning, sky clear, except on the horizon; between 12:22 p. m. and 12:41 p. m., seven exposures of, respectively, $8,10,12,13,14,16$, and $19 \mathrm{~min}$.

At 9 p. m., exposures Nos. 5, 6, and 7 showed erythema (No. 5, very faint). The next day, Nos. 6 and 7 (16 and $19 \mathrm{~min})$ showed slight pigmentation; exposure No. 5 (14 $\mathrm{min})$, which happened to be over a vein, was indefinite. The time of exposure for an M. P. E. was estimated at $15 \mathrm{~min}$.

During the first 8 min of the exposures, the sky was clear, and from the impulse recorder the average $\mathrm{u} . v . Q$ was $148 \mu \mathrm{w} / \mathrm{cm}^{2}$, or a total of $711,000 \mathrm{ergs} / \mathrm{cm}^{2}$. During the next $4 \mathrm{~min}$, a small fracto formed and disappeared near the sun; and during the next $7 \mathrm{~min}$, a larger, denser fracto cloud formed and moved to within a 
few degrees from the sun. From the impulse recorder, the u.v.Q was estimated to be $140 \mu \mathrm{w} / \mathrm{cm}^{2}$, or $589,000 \mathrm{ergs} / \mathrm{cm}^{2}$ in $7 \mathrm{~min}$, or a total of $1,300,000 \mathrm{ergs} / \mathrm{cm}^{2}$ in $15 \mathrm{~min}$. The maximum energy utilized in $16 \mathrm{~min}$ was $1,384,000 \mathrm{ergs} / \mathrm{cm}^{2}$, with slight tanning. The pigmentation produced by the exposure of $19 \min (1,634,000$ $\left.\mathrm{ergs} / \mathrm{cm}^{2}\right)$ was about as dark as that of the exposure of $18 \mathrm{~min}\left(1,730,000 \mathrm{ergs} / \mathrm{cm}^{2}\right)$ in test No. 2. Apparently the light breeze and cooler air did not dry the skin sufficiently to require an appreciably larger doseage to produce an M. P. E.

Test No. 4.-July 16, 1943; warm, no breeze, skin moist; sky cloudless, except fine cirrus low on southwest horizon; between 10:51 and 11:10 a. m. (air mass, $m=1.09$ ) seven exposures of, respectively, 10, 12, 13, 14, 15, 17, and $19 \mathrm{~min}$.

At 9 p. m., exposures Nos. 4 (14 min) to 7 showed light erythema that continued until noon the following day. The time of exposure for an M. P. E. was about $14 \mathrm{~min}$. The average intensity of sun and sky radiation was $136 \mu \mathrm{w} / \mathrm{cm}^{2}$, or a total of $(136 \times 840 \times 10=) 1,142,400 \mathrm{ergs} / \mathrm{cm}^{2}$. The maximum energy utilized in the exposure for $16 \mathrm{~min}$ (skin red the following noon) was 1,304,000 ergs $/ \mathrm{cm}^{2}$.

With a cloudless sky the ratio of solar to sky radiation was probably 1:1.2. The total energy required to produce an M. P. E. was somewhat less than in all the preceding tests. It is, of course, impossible to decide how much of this decrease in energy was due to a clearer sky that transmitted a relatively greater amount of the biologically more effective ultraviolet of short wavelengths (average barometer, $754 \mathrm{~mm}$, and presumably average ozone in the stratosphere [36]), and how much was caused by moisture on the skin, which facilitated penetration.

Test No. 5.-July 23, 1943; warm, light breeze, skin dry; sky clear, except a few fracto on southeast to southwest horizon; between 11:57 a. m. and 12:17 p. m. (air mass, $m=1.06$, barometer $754 \mathrm{~mm}$ ); seven exposures of, respectively, 10, 12, $13,14,15,17$, and $20 \mathrm{~min}$. The counter was set to record the impulses every minute. During the first 12 minutes, 129 impulses were recorded, representing an average intensity of $139 \mu \mathrm{w} / \mathrm{cm}^{2}$; the remainder of the time it was $143 \mu \mathrm{w} / \mathrm{cm}^{2}$.

At 9 p. m., exposures Nos. 7 (20 min; red), 6, 5, 4, and 3 were visible. The erythema of exposure No. 5 was weaker than No. 4 , and No. 3 was very faint. The following morning, exposures Nos. 7, 6, 5, and 4 (faint) were still visible, and by noon, Nos. 5 and 4 were very faint. Nos. $6(17 \mathrm{~min})$ and 7 were decidedly overexposed.

The energy used in producing an M. P. E. in 15 min (161 pulses; 1 impulse $\left.=7,800 \mathrm{ergs} / \mathrm{cm}^{2}\right)$ was $1,256,000 \mathrm{ergs} / \mathrm{cm}^{2}$. Granting that $16 \mathrm{~min}$ (172 impulses) was more nearly the time of exposure to produce an M. P. E., the energy used was $(7,800 \times 172=) 1,342,000 \mathrm{ergs} / \mathrm{cm}^{2}$. These values are more exact than in the preceding tests, from which they do not differ conspicuously.

Test No. 6.- September 18, 1943; cool light breeze, skin dry; sky cloudless, small corona; ratio of sky to solar radiation estimated to be 1:2; high barometer $(765 \mathrm{~mm})$ - probably low ozone; between $12: 00$ and $12: 30 \mathrm{p}$. m. (air mass, $m=1.25$ to 1.26) seven exposures of, respectively, 14, 17, 19, 21, 24, 27 and $30 \mathrm{~min}$. The intensity ranged from 93 to $96 \mu \mathrm{w} / \mathrm{cm}^{2}$ (see fig. 7).

The interesting part of this test was that none of these exposures showed erythema, and only the exposures of 24,27 , and 30 min showed a faint pigmentation, although the energy involved ranged from $1,340,000$ to $1,650,000$ ergs. It is well established that the sensitivity of the skin depends upon one's physical condition. In this case, the subject concerned was suffering from the after effects of hay fever, which presumably affected the erythemal response.

Test No. 7.-September 28, 1943; warm, no breeze, skin moist; sky cloudless, at times murky, white corona; ratio of sky to solar radiation estimated to be 2.0 to 2.5; high barometer $(760 \mathrm{~mm})$ for 2 days - no doubt low ozone in stratosphere; between $11: 55 \mathrm{a}$. m. and $1: 25 \mathrm{p}$. m. (air mass, $m=1.34$ to 1.44) seven exposures of, respectively, 20,30,40,50,60,75, and $90 \mathrm{~min}$. The solar and sky intensity decreased from $68 \mu \mathrm{w} / \mathrm{cm}^{2}$ at the start to $56 \mu \mathrm{w} / \mathrm{cm}^{2}$ during the last quarter-hour. During the second through the fifth exposure the average u. v. Q was $60 \mu \mathrm{w} / \mathrm{cm}^{2}$.

An interesting part of this test was that at the completion of the irradiation, exposures Nos. 7 to 2 (very faint) showed "heat" erythema. The next day, exposures Nos. 3 to 7, inclusive, were red and pigmented. Evidently the energy required to produce an M. P. E. was between exposure No. $2\left(1,144,500 \mathrm{ergs} / \mathrm{cm}^{2}\right)$ and exposure No. $3\left(1,504,500 \mathrm{ergs} / \mathrm{cm}^{2}\right)$, or about $1,300,000 \mathrm{ergs} / \mathrm{cm}^{2}$, which is in good agreement with earlier tests with ultraviolet that has traversed through smaller air masses. Apparently, the photoelectric response and the erythemal response do not differ greatly in their integration of the ultraviolet transmitted through air masses $m=1.05$ to $m=1.5$. 
Probably the most conspicuous result of this series of erythema tests is the observation that the total biologically effective ultraviolet energy in sky and solar radiation incident on a horizontal plane required to produce an M. P. E. is practically the same as that of ultraviolet solar radiation at normal incidence. This seems to indicate that, in spite of the above-mentioned uncertainties in the ultraviolet spectral-energy distribution of the source (sun and sky), the calibration of the ultraviolet-intensity meter in absolute value may not be in great error. One object in making these erythemal tests was to correlate the biological response with the radiometric measurements, so that if a correction is required in the latter, a similar correction can be applied to the M. P. E. evaluations.

\section{REFERENCES AND NOTES}

[1] At the Oxford Meeting (Sept. 12 to 15, 1936) of the International Commission on Solar Radiation (Organization Meteorologique Internationale) the senior writer was appointed the U. S. A. representative on a subcommission to investigate the cadmium photoelectric cell for measuring ultraviolet solar radiation for use in medicine [6]. In this connection acknowledgement is made to the Council on Physical Therapy of the American Medical Association for two grants-in-aid to develop a photoelectric ultraviolet-intensity meter with a flat, horizontal receiving surface of $\mathrm{Mg}[3,4]$, and to the American Philosophical Society for a subsequent grant-in-aid in the improvement of this type of ultraviolet-intensity meter, using $\mathrm{Zr}$-photoelectric cells.

[2] W. W. Coblentz and R. Stair, Measurements of ultraviolet solar radiation in Washington, 1936 to 1942, J. Research NBS 30, 435 (1943) RP1542.

[3] W. W. Coblentz and R. J. Cashman, A photoelectric cell for measuring ultraviolet solar and sky radiation on a horizontal plane, Bul. Am. Meteorol. Soc. 21, 149 (1940).

[4] W. W. Coblentz, F. R. Gracely, and R. Stair, Measurements of ultraviolet solar and sky radiation intensities in high latitudes, J. Research NBS 28, 581 (1942) RP1469.

[4a] Reference to the use of an automatic impulse ("traffic") counter and recorder is made in Tech. News Bul. NBS 289, p. 41 (May 1941). In figure 5 of J. Research NBS 31, 181 (1943) RP1557 is given a photograph of the interior of such a traffic recorder as recently applied by L. F. Curtiss and F. J. Davis in a counting method for the determination of small amounts of radium and of radon.

[5] H. C. Rentschler, An ultraviolet light meter, Proc. Am. Inst. Elec. Engrs. 49, 576 (1930); Trans. Illum, Engr. Soc. 25, 406 (1930).

[6] W. W. Coblentz, The spectral range of ultraviolet solar radiation useful in bioclimatology, Bul. Am. Meteorol. Soc. 22, 316 (1941).

[7] In conformity with recent terminology, in the present paper "phototube" is used as an abbreviation to designate the vacuum type of photoelectric cell, irrespective of the shape of the container, whether spherical or tubular in form.

[8] This type of construction was developed by H. C. Rentschler in connection with the pioneering measurements of ultraviolet radiation in American cities by James E. Ives and W. A. Gill (U. S. Public Health Service, Bulletin 233, March 1937); also the subsequent modifications by F. S. Brackett and his collaborators (Rev. Sci. Inst. 12, 87, 1941), including the mounting of all the parts in an evacuated vitreous envelope, and the substitution of a flat surface [3] for the half-cylinder cathode previously used.

[9] W. W. Coblentz and R. Stair, A portable ultraviolet-intensity meter, consisting of a balanced amplifier, photoelectric cell, and microammeter, BS J. Research 12, 23 (1934) RP647, [30].

[10] W. W. Coblentz and R. Stair, Factors affecting ultraviolet solar-radiation intensities J. Research NBS 15, 123 (1935) RP816.

[11] W. W. Coblentz and R. Stair, A standard source of ultraviolet radiation for calibrating photoelectric dosage intensity meters, J. Research NBS 16, 83 (1936) RP858.

[12] W. W. Coblentz, R. Stair, and J. M. Hogue, A balanced thermocouple and filter method of ultraviolet radiometry, with practical applications, BS J. Research 7, 723 (1931) RP370. 
A description is given of (a) the evaluation of ultraviolet solar radiation by means of a single thermocouple receiver [28] and a balanced (differential) thermopile receiver, (b) physiological tests of the erythematogenie effieieney of ultraviolet solar radiation, and (c) calibration of a photoelectrically operated impulse counter, in absolute units, by means of radiometric filter methods.

[13] W. W. Coblentz, R. Stair, and J. M. Hogue, Tests of a balanced thermocouple and filter radiometer as a standard ultraviolet dosage intensity meter, BS J. Research 8, 759 (1932) RP450.

Data are given on the erythematogenic efficiency of ultraviolet radiation from various artificial sources and from the sun.

[14] W. W. Coblentz and R. Stair, Evaluation of ultraviolet solar radiation of short wavelengths, J. Research NBS 16, 315 (1936) RP877.

Data are given showing a close agreement in the evaluation of ultraviolet solar radiation by means of (a) a balanced thermopile [12] calibrated in absolute units by means of a standard of thermal radiation [15], and (b) a Ti-photoelectric cell [9] calibrated in absolute value, against a standard of ultraviolet radiation [11].

[15] W. W. Coblentz and R. Stair, The present status of the standards of thermal radiation maintained by the National Bureau of Standard's, BS J. Research 11,79 (1933) RP578.

[16] W. W. Coblentz and R. Stair, Distribution of energy in the extreme ultraviolet of the solar spectrum, J. Research NBS 17, 1 (1936) RP899.

[17] W. W. Coblentz and R. Stair, Radiometric measurements of ultravrolet solar intensities in the stratosphere, Bul. Am. Meteorolog. Soc. 18, 345 (1937); Radiologica 1, 12 (1937).

[17a] R. Stair and W. W. Coblentz, Radiometric measurements of ultraviolet solar intensities in the stratosphere, J. Research NBS 20, 185 (1938) RP1075.

The papers [17] give a brief description of the methods used and a preliminary report of the results obtained in the stratosphere flights of 1937 . RP1075 gives the complete report of the results obtained.

[18] G. W. Bachman, School of Tropical Medicine, San Juan, Puerto Rico. Annual Report of the Director, 1936, 1938, 1939.

[19] G. W. Kenrick and H. Oritz, Measurements of ultraviolet solar radiation in Puerto Rico, Trans. Am. Geophys. Union (Meteorology Section) 38, 134 (1938).

[20] G. W. Kenrick and G. DelToro Jr., Studies in solar radiation and their relationship to biophysics and the general problem of climate and health, Puerto Rico J. Pub. Health Trop. Med. 16, 387 (1940).

[21] G. W. Kenrick, An electronic integrator for counting circuit contacts, Electronics 14, 33 (1941).

A description is given of an integrating circuit that averages the impulses per minute [5] and traces the values continuously on a Leeds Northrup chart recorder. This gives a graphical indication of ultraviolet intensity and its variations with solar heights, clouds, etc. [20].

[22] M. Luckiesh, A. H. Taylor, and G. P. Kerr, Ultraviolet energy in daylighta two-year record, J. Franklin Inst. 223, 699 (1937); A four-year record, J. Franklin Inst. 228, 425 (1939).

[23] F. Dannmeyer, Die ultraviolette Himmelsstrahlung in nördlichen Breiten, Strahlentherapie 35, 607 (1930).

[24] Acknowledgement is made to Glenn A. Greathouse, Bureau of Plant Industry, for the use of several of his impulse-counting machines when not in use in the field.

[25] H. H. Kimball and H. E. Hobbs, A new form of thermoelectric recording pyrheliometer, J. Opt. Soc. Am. \& Rev. Sci. Insts. 7, 707 (1923); Monthly Weather Rev. 51, 239 (1923).

[26] I. F. Hand, Review of U. S. Weather Bureau solar radiation investigations, Monthly Weather Rev. 65, 415 (1937).

[27] W. W. Coblentz, The hazard of burns from orificial ultraviolet applicators. Arch. Phys. Therapy 23, 149 (1942).

[28] W. W. Coblentz and R. Stair, Measurement of extreme ultraviolet solar radiation by a filter method. BS J. Research 6, 951 (1931) RP318.

Measurements are given of the biologically effective component of ultraviolet solar radiation, at high altitudes and at sea level, using an exclusion filter and a single thermocouple receiver, calibrated in absolute value by simultaneous measurements of the total incident solar radiation with a standardized pyrheliometer [12]. See ref [14] for corrections to these early data.

[29] Our task was greatly simplified by an extensive table of solar heights on different dates, supplied by I. F. Hand of the U. S. Weather Bureau. If such 
data are not obtainable from the local weather bureaus, the observer can use a theodolite.

[30] R. Stair and I. F. Hand, A stable photoelectric amplifier and its application in ultraviolet and ozone studies, Bul. Am. Meteorol. Soc. 22, 259 (1941).

This paper describes a Wheatstone bridge type of balanced direct-current photoelectric amplifier [9] adapted for operation on 110-volt a-c commercial power lines. The output meter may be a portable or recording type of microammeter, galvanometer, or potentiometer. A mechanical device is proposed to perform an intregation of ultraviolet solar and sky radiation that is accomplished by the electronic intregrating device [5] used in the present investigation - see also [21].

[31] R. Stair and W. O. Smith, A tungsten-in-quartz lamp and its applications in photoelectric radiometry, J. Research NBS 30, 449 (1943). RP 1543.

Description of a lamp consisting of a filament of tungsten wire inclosed in a spherical fused-quartz bulb proposed for use in irradiating large sized photoelectric receivers that are not readily calibrated for long-wave-length spectral response by means of filters, using a tungsten-ribbon-filament lamp [2, 32] having a fused-quartz window.

[32] R. Stair and W. W. Coblentz, Spectral Energy Distribution of the Standard Comparison Lamp Used in Evaluating the Flash Spectrum of the Solar Eclipse of 1940, Nat. Geographic Soc., Contrib. Tech. Papers, Solar Eclipse Series, No. 2, p. 48 (1942).

Description of spectral-energy measurements on the standard tungsten-ribbon lamp used in evaluating the photographic film densities of the flash spectrum in the range of wavelengths extending from 3450 to $5350 \mathrm{~A}$; also a discussion of the spectral emissivities of tungsten by the junior author [34].

[33] R. Stair and I. F. Hand, Methods and results of ozone measurements over Mount Evans, Colo., Monthly Weather Rev. 67, 331 (1939).

A description is given of a "trial-and-error" method of calculating the amount of ozone in the stratosphere, based upon measurements with an ultraviolet intensity meter and filters (ref. [9] and fig. 1 in [10]). Unfortunately, cloudy weather prevented extensive (only 2) all-day measurements; but from the limited results obtained, the method appears promising.

[34] W. W. Coblentz, The emissivity and energy distribution of tungsten in the photographic region of the spectrum, Pub. Am. Astronom. Soc. 10, 222 (1942).

Data are given on the spectral intensities of a standard tungsten-ribbon lamp, operated at $2,900^{\circ} \mathrm{K}$, in the spectral range of wavelengths extending from 2500 to $11000 \mathrm{~A}$, for use as a source of comparison in obtaining the spectral-energy distribution of celestial objects; also in determining by a filter method the longwavelength spectral response of photoelectric cells used in ultraviolet-dosageintensity meters [2].

[35] W. W. Coblentz, Report to the Council on Physical Therapy on heliotherapy methods in some European sanatoriums, J. Am. Med. Assn. 100, 410 (1933).

At A. Rollier's sanatoriums in Leysin, Switzerland, in 1932, the writer saw a nontanning "Venetian blond" patient with surgical tuberculosis who was healed by sky radiation. Of course, the healing process was slower than by direct solar radiation, which could not be applied because of the weakness of the patient, whose nontanning skin could not tolerate direct solar radiation.

[36] A. R. Meetham, The correlation of the amount of ozone with other characteristics of the atmosphere, Quart. J. Roy. Meteorolog. Soc. (London) 63, 289 (1937).

This paper gives an important discussion of phenomena in the stratosphere and their relation with observed sea level barometeric pressures. Dobson in the same volume, p. 305, points out that it is a matter of doubt whether the amount of ozone is affected by weather conditions or vice versa. See also an earlier paper by E. Kidson, Proc. Roy. Soc. (London) [A] 129, 422 (1930). In recent times a better correlation is found between movements of tropical and polar air masses, and ozone concentration.

[37] In this connection, reference is made to a paper by M. Schein and B. Stoll, On Rayleigh scattering of zenith skylight, Helv. Physic. Acta 7, 672 (1934), and to a discussion of the "reversal effect" (umkehreffekt) by F. W. P. Götz, Die vertikale verteilung des atmosphärischen ozons, Ergeb. Kosmischen Physik III. 253 (1938).

Washington, December 31, 1943. 